\title{
FACTORES Y AGENTES GENERADORES DE CORRUPCIÓN ADMINISTRATIVA EN EL DEPARTAMENTO DEL HUILA
}

Doctorado en derecho constitucional de la Universidad de Paris (Sorbona). Director del Grupo Nuevas Visiones del Derecho (Categoría B Colciencias). Docente investigador de la Universidad Surcolombiana.

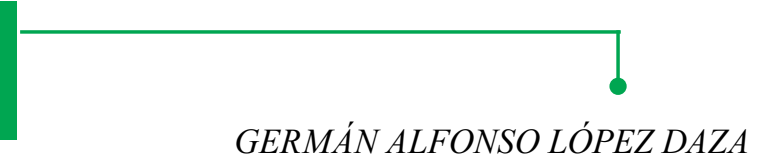

RESUMEN

La corrupción, definida como el aprovechamiento de los recursos públicos o de la condición de servidor público en beneficio particular, ha sido un tema muy recurrente a raíz de los continuos escándalos que en forma periódica, los medios de comunicación publicitan a veces de manera sensacionalista o morbosa. Este fenómeno que no es nuevo, pero que en los últimos años ha adquirido importancia global se ha convertido en tema de estudio pues se convierte cada vez más en un de los peores males de la sociedad moderna, caracterizada por al internacionalización de la economía y la formación de grandes bloques de países, aspectos estos que en forma similar se han reflejado en el tema de la corrupción.

A nivel regional se habla continuamente de esta problemática, pero sin que existan estudios serios acerca de los índices, causales, instituciones y otros factores que aquejan la administración pública, lo cual refleja la necesidad de una investigación que concluya e indique cuál ha sido el manejo y el actuar de quienes están investidos por la manta del poder publico, estableciendo con ello los índices, las posibles causas y factores generadores de este problema

Es por lo anterior que a esta investigación se identificó y analizó los principales agentes y factores generadores de corrupción en la gestión pública, según los fallos proferidos por la Procuraduría y Contraloría a nivel Departamental y local así como en la Auditoría.

Los resultados de la investigación demuestran que la corrupción en el Huila no se encuentra en cifras demasiado altas, pues la mayor parte de investigaciones y sanciones se hacen sobre comportamientos no coincidentes con las características de la corrupción administrativa.

\section{PALABRAS CLAVE}

Corrupción, corrupción administrativa, transparencia, órganos de control, control ciudadano, corrupción en el Huila. 


\section{ABSTRACT}

Lacorrupción, definida comoelaprovechamiento de los recursos públicos o de la condición de servidor público en beneficio particular, ha sido un tema muy recurrente a raíz de los continuos escándalos que en forma periódica, los medios de comunicación publicitan a veces de manera sensacionalista o morbosa. Este fenómeno que no es nuevo, pero que en los últimos años ha adquirido importancia global se ha convertido en tema de estudio pues se convierte cada vez más en un de los peores males de la sociedad moderna, caracterizada por al internacionalización de la economía y la formación de grandes bloques de países, aspectos estos que en forma similar se han reflejado en el tema de la corrupción.

A nivel regional se habla continuamente de esta problemática, pero sin que existan estudios serios acerca de los índices, causales, instituciones y otros factores que aquejan la administración pública, lo cual refleja la necesidad de una investigación que concluya e indique cuál ha sido el manejo y el actuar de quienes están investidos por la manta del poder publico, estableciendo con ello los índices, las posibles causas y factores generadores de este problema

Es por lo anterior que a esta investigación se identificó y analizó los principales agentes y factores generadores de corrupción en la gestión pública, según los fallos proferidos por la Procuraduría y Contraloría a nivel Departamental y local así como en la Auditoría.

Los resultados de la investigación demuestran que la corrupción en el Huila no se encuentra en cifras demasiado altas, pues la mayor parte de investigaciones y sanciones se hacen sobre comportamientos no coincidentes con las características de la corrupción administrativa.

\section{KEY WORDS}

Corrupción, corrupción administrativa, transparencia, órganos de control, control ciudadano, corrupción en el Huila.

\section{INTRODUCCIÓN}

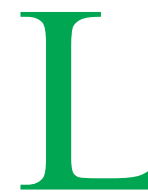

a corrupción no es un tema nuevo, aunque solo recientemente ha surgido como una cuestión de interés global. Ocurre, con variada intensidad, en democracias y dictaduras militares, en todos los niveles de desarrollo y en todos los tipos de sistemas económicos. No existe ninguna correlación simple entre los niveles de democracia y los niveles de corrupción. La democracia no otorga ninguna inmunización automática contra los malos manejos públicos, pero a la larga engendra anticuerpos más poderosos contra la corrupción que los sistemas en los que las libertades políticas están reprimidas.

Entre las situaciones que propician la corrupción se podrían citar entre otras, la ausencia de tipificación de conductas que incrementa su baja persecución legal, el derecho a la libertad de información que es muy limitado en los países del tercer mundo y la debilidad de las instituciones como principal cultivo de la corrupción, así como una cultura del dinero fácil y la complicidad de la ciudadanía ante el silencio encubridor.

Peter Eigen, fundador de Transparency Internacional, ha expresado en forma vehemente:

"La corrupción es un vicio de nuestra época que muestra su desagradable rostro en todas sus partes. Se halla en su raíz misma de casi todos los problemas importantes $-\mathrm{O}$ al menos impide su resolución- y actúa de manera especialmente devastadora en las regiones más pobres del mundo, donde mantiene atrapados a millones de seres humanos en la miseria, la pobreza, la enfermedad, la explotación y brutales conflictos."

La CORRUPCIÓN se describe como toda aquella acción u omisión del servidor público que lo lleva a desviarse de los deberes formales de su cargo con el objeto de obtener beneficios pecuniarios, políticos, o de posición social 
así como cualquier utilización en beneficio personal o político de información privilegiada, influencias u oportunidades.

Es indiscutible el malestar que genera en los ciudadanos la practica por parte de sus representantes de la anterior definición, más aún, si se tiene en cuenta que se desconoce y se burla con ello la autoridad que el pueblo ejerce a través del sufragio, como característica propia de un sistema en donde el pueblo entrega a sus representantes el poder público para que lo ejerzan en su nombre y representación.

La desilusión es grande al encontrar ese pueblo elector, que los elegidos continúan con esa línea de corrupción y de complicidad de sus antecesores; se conserva el status quo, solo cambian, en ocasiones los sujetos responsables del manejo. El desgreño administrativo continúa, el atraso se profundiza y el control ciudadano no despega.

Muchos focos de corrupción se destapan periódicamente, luego se olvidan para aparecer más tarde otros nuevos. Principal problema se sitúa en la contratación estatal, por donde se van las esperanzas de progreso de millones de colombianos, aquí está el principal problema de corrupción y ejemplos de ello abundan en nuestro país tales como Ferrovías, Caprecom, Foncolpuertos, Termorrio, Dragacol, o para no ir muy lejos, los sonados casos de corrupción del Hospital Universitario de Neiva, de Empresas Públicas, la Alcaldía de Neiva o la misma Universidad Surcolombiana, solamente para hablar de algunos casos.

Todo lo anterior se ve parcialmente reflejado en los índices y en los fallos emitidos por la Procuraduría, la Contraloría y la Auditoria, entidades que tienen la misión constitucional de combatir la corrupción desde diferentes flancos y que a pesar de sus debilidades presupuestales, administrativas y de personal, han ejecutado un trabajo valioso en la búsqueda de unos procesos administrativos más transparentes.
La presente investigación pretendió abordar un estudio de la corrupción administrativa desde la perspectiva analítica de los fallos de los entes de control fiscal y disciplinario, analizando una muestra de los procesos de los años 2004, 2005 y 2006. Del mismo modo se evidencia que la corrupción que existe en estos momentos, nos refleja la necesidad de una investigación que concluya e indique cuál ha sido el manejo y el actuar de quienes están investidos por la manta del poder público, estableciendo con ello, las posibles consecuencias que se generan en la sociedad y en la misma administración del Estado.

Nos corresponde, por tanto, indagar si este fenómeno es producto de una inexistencia de fiscalización y control directo y personal entre el elector primario y su delegatario o si por el contrario dicho control se ejerce, pero resultan ser ineficaces las medidas que se llevan a cabo para contrarrestar este tipo de comportamientos, generando con ello una conducta repetitiva, aceptada por la sociedad y trasmitida de generación en generación, propagando en el territorio nacional y por consiguiente en nuestro departamento altos niveles de subdesarrollo, elevadas tazas de desempleo, falta de educación e inconformismo en la sociedad.

El presente documento presenta en primer lugar unas precisiones de tipo teórico sobre el contenido y alcance del concepto, así como los desarrollos doctrinales. Seguidamente, se expondrán los resultados de la investigación con el respectivo análisis, iniciando con los del control fiscal (Contraloría municipal, Contraloría Departamental, Contraloría General de la República), enseguida con el control disciplinario (Procuraduría Provincial y Regional) para finalizar con la Auditoría General de la República. Posteriormente se documentará el análisis jurisprudencial de la Corte Constitucional y el Consejo de Estado sobre el tema y finalmente se harán algunas conclusiones. 
Sería muy arrogante por parte del Grupo dar soluciones definitivas a tan complejo tema; sin embargo, los resultados estadísticos del control estatal y su respectivo análisis en tres años, podrá dar una idea del estado actual de la problemática y tal vez sirva de elemento para continuar un debate que se pretende abrir con esta publicación.

\section{PROBLEMA DE INVESTIGACIÓN}

¿Cuáles son los agentes y factores generadores de corrupción administrativa en el Departamento del Huila, desde la perspectiva de las decisiones de la Procuraduría, Contraloría y Auditoría?

\section{ANTECEDENTES Y JUSTIFICACIÓN}

La corrupción se describe como toda aquella acción u omisión del servidor público que lo lleva a desviarse de los deberes formales de su cargo con el objeto de obtener beneficios pecuniarios, políticos, o de posición social, así como cualquier utilización en beneficio personal o político de información privilegiada, influencias u oportunidades ${ }^{2}$.

Es por ello que generalmente se relaciona la corrupción con términos tales como la deshonestidad, ausencia de valores y principios, engaños, en fin con todo aquello que puede perjudicar la sociedad por cuanto está relacionado con el erario público; es de tener en cuenta que no es un problema reciente, siempre existirá mientras no se ataque desde sus orígenes, entre otros como el clientelismo y la financiación de las campañas políticas por parte de los que en el futuro serán los grandes contratistas del Estado.

Las cifras demuestran el creciente y desbordado número de personas investigadas por corrupción como son: 7.981 alcaldes y ex alcaldes, 745 concejales, 350 diputados, 2.688 contratistas, 1.702 gerentes y funcionarios de empresas públicas y 1.047 tesoreros municipales.

De este modo, existe una impresionante realidad nacional cuyo ámbito regional en el Departamento del Huila no se conoce en cifras, pero se advierte ante el conocimiento directo de tal situación.

La corrupción aumenta con el grado de ineficacia en el cual se desarrolla la actividad de las instituciones, con la discrecionalidad de los funcionarios, con el grado de monopolio sobre los servicios que prestan, con los ingresos que pueden obtenerse en las actividades corruptas, con una baja probabilidad de ser descubierto, con unos bajos castigos para las actividades corruptas y con una baja sanción social sobre los individuos corruptos.

Por consiguiente la ineficacia producto de altos índices de corrupción reducen la calidad del servicio que las entidades prestan al público, creando espacios para que el ciudadano ofrezca dinero o estímulos a cambio de la obtención del servicio, permitiendo que el funcionario se involucre en este tipo de situaciones o actividades; a contrario sensu, la ineficiencia, está asociada a la carencia o el pobre funcionamiento de los sistemas de planeación y de control.

De otra parte, el Grupo Nuevas Visiones del Derecho advirtió la carencia total de trabajos investigativos en esta área en el Departamento del Huila; en el marco nacional se conocen muy pocos trabajos realizados por Grupos de Investigación registrados en el Grup Lac de Colciencias. Tales trabajos tratan el tema de manera muy genérica y teórica sin adentrarse en cifras ni en análisis de datos obtenidos en campo ni menos en la situación del departamento del Huila.

A título de ejemplo podemos mencionar el trabajo de maestría titulado "Análisis de la corrupción

2 Revista Jurídica Alé-Kuma No. 14 año 2002. 
a partir de los modelos teóricos y empíricos: un acercamiento crítico a la medición de la corrupción" elaborado por Andrea Franco Correa. Este trabajo de investigación toma elementos conceptuales extranjeros y trata de elaborar un modelo para medir la corrupción. Así mismo podemos citar el trabajo de tesis de grado denominado "Aproximación al estado del arte del concepto transparencia", elaborado por Miguel David Hincapié Elejalde el cual hace un trabajo bibliográfico sobre el alcance del concepto transparencia, muy ligado al tema de corrupción.

Teniendo en cuenta las consideraciones anteriores, se concluye que un proyecto de investigación sobre este tema se hace necesario, para establecer y generar un conocimiento que nos aporte un análisis sobre este fenómeno que afecta nuestras instituciones y así contribuir con un diagnóstico serio, académico del mismo que tanto afecta nuestra sociedad.

\section{OBJETIVOS}

\subsection{OBJETIVO GENERAL}

Identificar y analizar los principales factores de corrupción en la gestión pública, según los fallos proferidos por la Procuraduría, Contraloría y Auditoria, así como determinar los agentes que más inciden o generan dicha situación.

\subsection{OBJETIVOS ESPECIFICOS}

- Consultar y analizar los fallos en los que se observe de manera clara la corrupción en la gestión pública, durante los años 2004, 2005 y 2006

- Realizar un diagnóstico de los factores o principales causas que influyen a nivel local y departamental para que se de el fenómeno de la corrupción.

- Analizar el rol que cumplen la Procuraduría y Contraloría a nivel Departamental y local en la lucha contra la corrupción y su consecuente control.

- Identificar y categorizar los sujetos involucrados en los fallos por corrupción.

\section{FUNDAMENTO TEÓRICO}

\subsection{ACEPCIONES Y ALCANCE DEL TERMINO CORRUPCIÓN}

Transparencia internacional ha definido el término corrupción, adoptado por varios tratadistas como Susan Rose-Ackerman ${ }^{3}$ y Peter Eigen ${ }^{4}$, como el uso incorrecto del poder público para obtener beneficios privados.

Mario Iván Algarra Lobo $^{5}$ acude al sentido etimológico del vocablo, el cual viene del latín corruptus, que significa descomposición, podredumbe o desintegración. Expresa que en un sentido más amplio denota algo objeto de ruina, defectuoso, con vicios de degradamiento. El mismo autor acude a la Enciclopedia de ciencias sociales de 1931 que dice que la corrupción ocurre cuando el poder público ha sido utilizado para provechos personales. También cita la siguiente: corrupción es el uso del poder público para sacar ventajas personales de tal forma que transgrede las reglas formales de la ley. Finalmente fija la propia en estos términos: toda desviación del poder que ha sido depositado por la colectividad en una persona, independientemente del fin que sea buscado - provecho personal o de terceros- y su

3 ROSE-ACKERMAN Susan. La corrupción y los Gobiernos. Causas, consecuencias y reforma. Madrid: Siglo XXI de España Editores, Pág.15.

4 EIGEN, Peter. Las redes de la corrupción. La sociedad civil contra los abusos del poder. Barcelona: Editorial Planeta, 2003, Pág.15.

5 ALGARRA LOBO, Iván. No más corrupción. Estrategia preventiva para combatirla. Bogotá: Ediciones Jurídicas Gustavo Ibáñez, 2005, Pág.32. 
posterior utilización en finalidades diferentes a las del bienestar de la colectividad ${ }^{6}$.

El Banco Mundial ${ }^{7}$ por su parte ha expresado que la corrupción es un gran obstáculo para el desarrollo económico y social. La corrupción mina el desarrollo, pues distorsiona el estado de derecho y debilita los principios institucionales básicos en que se basa el crecimiento de la economía.

Rodrigo Querubín Londoño ${ }^{8}$ adopta la misma de Transparencia por Colombia que la define como el abuso de posiciones de poder o de confianza, para beneficio particular en detrimento del interés colectivo, realizado a través de ofrecer o solicitar, entregar o recibir, bienes en dinero o en especie, en servicios o beneficios, a cambio de acciones, decisiones u omisiones.

El Gobierno Colombiano a través de su Programa Presidencial de Lucha contra la corrupción el cual es liderado por la Vicepresidencia de la República, elaboró una Propuesta de política de Estado para el control de la corrupción ${ }^{9}$. Dicha propuesta hizo diferentes aproximaciones a la definición de corrupción. Se partió de la base de que corrupción es el aprovechamiento de los recursos públicos o de la condición de servidor público en beneficio particular.

La definición de este concepto es un ejercicio complejo, pero dentro de las diversas aproximaciones encontramos algunos elementos que ayudan a redefinirla. Uno de ellos es el uso abusivo de los recursos públicos para beneficio privado a través de transacciones clandestinas que implican la violación de algún modelo de comportamiento.
La concepción que se tiene sobre corrupción también varía dependiendo de un momento histórico, tal como es el caso de lo ocurrido a raíz de los atentados del 11 de septiembre. A partir de este momento la corrupción se identifica claramente como un instrumento del terrorismo, pues es lo que impide con sus cortinas que se atrapen a verdaderos culpables y lo que disminuye claramente la velocidad del sistema judicial. La corrupción mina la confianza en las instituciones, distorsiona la competencia leal, es herramienta de la delincuencia común, también desestabiliza economías y aniquila los valores de las empresas honradas.

Son actos corruptos aquellos en los cuales además de no existir publicidad no existe una relación directa entre la toma de la decisión y un interés de carácter general, donde se violan procesos democráticos y solo se da la oportunidad de defender sus intereses a quienes tienen poder económico.

En la Convención para la Lucha de la Corrupción en el extranjero ${ }^{10}$, se motiva a los miembros a hacer ver como un delito la conducta en que una persona sin intención ofrece, promete $\mathrm{o}$ proporciona a un funcionario público extranjero cualquier ventaja indebida, pecuniaria o de otra índole, ya sea en forma directa o a través de intermediarios y ya tenga como destinatario a dicho funcionario o a una tercera persona, a fin de que el citado funcionario haga o deje hacer algo respecto al cumplimiento de sus funciones oficiales, con el propósito de obtener o retener una ventaja impropia, comercial o de otra naturaleza, en la conducción de los negocios internacionales.

\footnotetext{
ob.cit., Pág. 33.

www.worldbank.org/wbi/governance/esp

QUERUBIN LONDOÑO, Rodrigo. La lucha anticorrupción y la ética pública y privada. Bogotá: Editorial Carrera $7^{a}$, primera edición 2005, Pág. 3.

9 www.vicepresidencia.gov.co

10 La Convención de Organización de Cooperación y Desarrollo Económico (OCDE) sobre la Lucha contra la Corrupción de Funcionarios Públicos Extranjeros en las Transacciones Comerciales Internacionales, ha sido una prioridad de largo plazo para el gobierno de Estados Unidos. Este país fue el primero en criminalizar el soborno de funcionarios públicos en el extranjero mediante la promulgación de la Ley contra las Prácticas de Corrupción en el Extranjero (FCPA) en 1977. Desde la negociación de la convención, en 1997, casi los 35 países signatarios han ratificado la convención y han promulgado leyes que criminalizan el soborno de funcionarios públicos extranjeros. Estados Unidos tiene un papel de liderato en la promoción de la implementación y aplicación de esta convención en el Grupo de Trabajo de la OCDE sobre Soborno, que está compuesto de países signatarios de la convención y que está a cargo del monitoreo de su implementación.
} 
Jorge Malem Seña por su parte define los actos de corrupción "...como aquellos que constituyen la violación, activa o pasiva, de un deber posicional o del incumplimiento de alguna función específica realizados en un marco de discreción con el objeto de obtener un beneficio extraposicional, cualquiera sea su naturaleza."11

Para Jorge Malem Seña, la corrupción no debe ser confundida con medidas estatales de carácter promocional. El Estado debe y puede recurrir en ocasiones a las llamadas técnicas de alentarmiento o de estímulo, que como lo manifiesta Norberto Bobbio "Son técnicas que no actúan directamente sobre la practica valiosa o disvaliosa, sino que trata de influir en los destinatarios a través del fomento de otras acciones que hagan más atractivas las prácticas deseadas por el Estado mediante el otorgamiento de premios o de sanciones positivas"12 Como ejemplo de ello se tendrían las leyes de incentivos fiscales. Su carácter de política promocional debe ser general, al contrario del carácter del acto de corrupción que es individual.

La corrupción tampoco puede ser confundida con un uso desviado del poder. Esto no se debe entender como corrupción cuando no tenga por objeto la percepción de un beneficio extrainstitucional para la autoridad en cuestión ${ }^{13}$.

La corrupción no debe asimilarse al clientelismo político o de otro tipo. Según Mario Caciagli, el clientelismo es una relación diádica en la cual un agente, en posición de superioridad, utiliza su influencia y sus recursos para dar protección y seguridad a otro agente, que está en posición de inferioridad, a cambio de servicios, lealtades y $\operatorname{apoyos}^{14}$.

La recepción de regalos, recompensas o compensación económica o de otro tipo, por parte de un funcionario público, político o particular en virtud del desempeño de su trabajo se ha considerado en no pocas ocasiones, como actos genéricos de corrupción. En la actividad privada se suele gratificar a directivos y empleados con viajes u obsequios tomados como una forma de reconocimiento. Se considera que las dádivas se realizan pensando en la correspondencia recíproca de favores pasados o futuros. Además de establecer buenas relaciones personales e institucionales, pueden ser una muestra de prestigio personal, puede satisfacer ciertas exigencias religiosas o puede construir una manera de expresar ciertos comportamientos simbólicos. La aceptación de un obsequio o dádiva es un acto libre pero en el caso de funcionarios del Estado es perniciosa.

Malem Seña ${ }^{15}$ expresa como actos de corrupción, las diferencias entre la recepción, ofrecimiento y dación de propinas. Las propinas se entregan a empleados de rango bajo y posterior a la ejecución de una función, acá se guarda relación de cierta manera con el servicio efectuado. Pero cuado el monto no guarda la proporción entre lo efectuado, se puede entender como si fuera un soborno. Es de vital importancia para entender esta clasificación tener los conceptos claros de soborno, regalo y propina, aunque en muchos casos se intente disfrazar lo uno con etiqueta de otro.

Para que un acto sea catalogado como corrupto debe cumplir con ciertas características:

- Violación de un deber posicional, es decir la trasgresión de deberes impuestos a cargo del sujeto.

- Existencia de un sistema normativo que sirva de marco legal ya que la noción de corrupción es parasitaria o depende de la existencia de este. Por esta razón la corrupción puede tener una naturaleza económica, política, jurídica o ética o participar de distintos niveles a la vez.

11 MALEN SEÑA, Jorge. La corrupción. Aspectos éticos, económicos, políticos y jurídicos. Barcelona: Editorial Gedisa, 2002, pag. 32 y ss.

12 BOBBIO, Norberto. Contribución a la teoría del derecho. Edición a cargo de Alfonso Ruiz Miguel. Valencia: Fernando Torres Editor, 1980, capitulos XVII y XVIII.

13 MALEN SEÑA, ob.cit., pag. 24.

14 CACIAGLI, Mario. Clientelismo, corrupción y criminalidad organizada. Madrid: Centro de Estudios Constitucionales, 1996, pag.18. 15 MALEN SEÑA, ob.cit. pag. 26. 
- Un acto corrupto debe estar inmerso dentro del campo de lo antijurídico. Que un acto de corrupción sea legal o ilegal, desde un punto de vista penal, dependerá del tratamiento que el sistema punitivo ofrezca a las reglas del sistema normativo de referencia. En otras palabras, debe existir concordancia entre el deber y el delito que castiga el incumplimiento del deber.

- Losactos decorrupción siempre están vinculados a la expectativa de obtener un beneficio extraposicional, que no necesariamente debe ser de carácter económico; también puede ser político, profesional, sexual, etcétera.

- El secreto es un ingrediente básico en los actos de corrupción, pues este debeejecutarse en un marco de discreción en un intento por ocultar la acción corrupta. En aquellos casos en que se intenta alejarse de las normas del sistema de referencia, se sabe que se practican ampliamente pero casi nunca se sancionan. Por su carga negativa son sustraídas del conocimiento público.

La corrupción en alta escala consiste en la venta de decisiones que hacen personas poderosas, amparadas por una prensa no independiente $\mathrm{y}$ en general por los sistemas de comunicación influenciados por capitales.

Según Malen Seña, los actos de corrupción se pueden presentar:

- Por necesidad, conveniencia o beneficio.

- Puede ser política o, (aunque no en todos los casos) económica. Se tiene en cuenta la acción, su motivación y la regla violada.

- Según la percepción que las elites y la opinión pública de un país tienen de ciertos actos corruptos. Depende pues de una evaluación normativa y así se distingue corrupción negra, blanca o gris. Este tipo surge a partir del nivel de aprobación, aceptación o reproche del acto corrupto, por parte de la sociedad en sus diferentes niveles.

\section{METODOLOGIA}

Teniendo en cuenta la problemática que se definió en el proyecto aprobado por la Vicerrectoría de Investigación, el Grupo Nuevas Visiones del Derecho procedió inicialmente a aplicar una prueba piloto a fin de ajustar el instrumento elaborado para recaudar la información.

Paralelamente se ofició a los organismos de control, es decir a la Procuraduría Provincial de Neiva, Procuraduría Regional, Contraloría Municipal de Neiva, Contraloría General del Departamento del Huila, Contraloría General de la República y Auditoría General de la República, con el fin de solicitarles la información del universo que componían los años fijados para la investigación.

En efecto, cada entidad respondió y nos informó la cantidad de procesos por años, con los datos que se citan a continuación.

\subsection{POBLACIÓN Y MUESTRA:}

\begin{tabular}{|c|c|c|}
\hline \multicolumn{3}{|c|}{ Procuraduría Provincial de Neiva } \\
\hline & $\begin{array}{c}\text { Fallos } \\
\text { absolutorios }\end{array}$ & $\begin{array}{c}\text { Fallos } \\
\text { sancionatorios }\end{array}$ \\
\hline $\begin{array}{c}\text { Año } \\
2004\end{array}$ & 28 & 23 \\
\hline $\begin{array}{c}\text { Año } \\
2005\end{array}$ & 36 & 19 \\
\hline $\begin{array}{c}\text { Año } \\
2006\end{array}$ & 25 & 8 \\
\hline
\end{tabular}

\begin{tabular}{|c|c|c|c|}
\hline \multicolumn{4}{|c|}{ Procuraduría Regional del Huila } \\
\hline & $\begin{array}{c}\text { Fallos } \\
\text { absolutorios }\end{array}$ & $\begin{array}{c}\text { Fallos } \\
\text { sancionatorios }\end{array}$ & Archivos \\
\hline $\begin{array}{c}\text { Año } \\
2004\end{array}$ & 19 & 60 & 205 \\
\hline $\begin{array}{c}\text { Año } \\
2005\end{array}$ & 39 & 32 & 158 \\
\hline $\begin{array}{c}\text { Año } \\
2006\end{array}$ & 40 & 25 & 173 \\
\hline
\end{tabular}

16 Oficio No.2114 de 2007 suscrito por Jorge Elicer Andrade Reina Secretario Provincial Neiva.

17 Oficio No.D.706 de 2007 suscrito por Delia del Socorro Cedeño Poveda. 


\begin{tabular}{|l|c|c|c|}
\hline \multicolumn{4}{|c|}{ Contraloría Municipal de Neiva18 } \\
\hline Consolidado & $\begin{array}{c}\text { Año } \\
2004\end{array}$ & $\begin{array}{c}\text { Año } \\
2005\end{array}$ & $\begin{array}{c}\text { Año } \\
2006\end{array}$ \\
\hline $\begin{array}{l}\text { Fallos con } \\
\text { responsabilidad }\end{array}$ & 9 & 1 & 1 \\
\hline $\begin{array}{l}\text { Fallos sin } \\
\text { responsabilidad }\end{array}$ & 5 & 1 & \\
\hline Archivos & 5 & 4 & 10 \\
\hline $\begin{array}{l}\text { Cesación de la } \\
\text { acción fiscal }\end{array}$ & 4 & 4 & 1 \\
\hline $\begin{array}{l}\text { Sanción con } \\
\text { responsabilidad fiscal }\end{array}$ & $\$ 1.568 .715 .802$ & $\$ 4.044 .960$ & $\$ 1.142 .501$ \\
\hline Total & 23 & 10 & 12 \\
\hline
\end{tabular}

\begin{tabular}{|l|c|c|c|}
\hline \multicolumn{4}{|c|}{ Contraloría Departamental del Huila ${ }^{19}$} \\
\hline Consolidado & Año 2004 & Año 2005 & Año 2006 \\
\hline $\begin{array}{l}\text { Fallos con } \\
\text { responsabilidad }\end{array}$ & 10 & 7 & 18 \\
$(\$ 195.268 .736 .50)$ & $(\$ 65.561 .024 .75)$ & $(\$ 428.075 .147)$ \\
\hline $\begin{array}{l}\text { Fallos sin } \\
\text { responsabilidad }\end{array}$ & 1 & 9 & 15 \\
\hline Archivos & 50 & 30 & 28 \\
\hline Total & 61 & 46 & 61 \\
\hline
\end{tabular}

\begin{tabular}{|l|c|c|c|}
\hline \multicolumn{4}{|c|}{ Contraloría General de la República ${ }^{20}$} \\
\hline Consolidado & Año 2004 & Año 2005 & Año 2006 \\
\hline $\begin{array}{l}\text { Fallos con } \\
\text { responsabilidad }\end{array}$ & 10 & 6 & 4 \\
$(\$ 72.207 .695)$ & $(\$ 460.661 .876)$ & $(\$ 45.555 .864)$ \\
\hline $\begin{array}{l}\text { Fallos sin } \\
\text { responsabilidad }\end{array}$ & 7 & 7 & 5 \\
\hline Archivos & 11 & 11 & 13 \\
\hline Total & 28 & 24 & 22 \\
\hline
\end{tabular}

\begin{tabular}{|l|c|c|c|c|}
\hline \multicolumn{5}{|c|}{ AUDITORIA GENERAL DE LA REPUBLICA } \\
\hline Consolidado & $\begin{array}{c}\text { Año } \\
2004\end{array}$ & $\begin{array}{c}\text { Año } \\
2005\end{array}$ & $\begin{array}{c}\text { Año } \\
2006\end{array}$ & Año 2007 \\
\hline $\begin{array}{l}\text { Fallos con } \\
\text { responsabilidad }\end{array}$ & 0 & 0 & $\$ 5.430 .000$ & $\$ 53.713 .720$ \\
\hline $\begin{array}{l}\text { Fallos sin } \\
\text { responsabilidad }\end{array}$ & 0 & 0 & 1 & 1 \\
\hline Archivos & 0 & 4 & 0 & 0 \\
\hline Total & 0 & 4 & 0 & 1 \\
\hline
\end{tabular}

El Grupo distribuyó las entidades entre los miembros del semillero Investigio, a fin de que aplicaran el instrumento a una muestra aleatoria de procesos que cursaron en los tres años de análisis.

Inicialmente se pretendió tomar un número fijo de procesos por año y que correspondiera a un porcentaje del universo; sin embargo después de haber iniciado la aplicación del instrumento, el Grupo se percató que en muchos casos, cada proceso tenía más de un sujeto procesal, por lo que la idea inicial de hallar un porcentaje fijo sobre el universo total no se pudo llevar a cabo.

Finalmente, se llevó a cabo la aplicación de los instrumentos sobre los individuos involucrados en procesos disciplinarios y fiscales, los cuales quedaron distribuidos por años así:

\section{CONTRALORÍA MUNICIPAL}

\begin{tabular}{|c|c|c|c|}
\hline $\begin{array}{c}\text { AÑO } \\
2004\end{array}$ & AÑO 2005 & $\begin{array}{c}\text { AÑO } \\
2006\end{array}$ & TOTAL \\
\hline 37 & 21 & 29 & 87 \\
\hline
\end{tabular}

CONTRALORÍA DEPARTAMENTAL

\begin{tabular}{|c|c|c|c|}
\hline $\begin{array}{c}\text { AÑO } \\
2004\end{array}$ & AÑO 2005 & AÑO 2006 & TOTAL \\
\hline 58 & 41 & 81 & 180 \\
\hline
\end{tabular}

CONTRALORÍA GENERAL DE LA REPÚBLICA

\begin{tabular}{|c|c|c|c|}
\hline $\begin{array}{c}\text { AÑO } \\
2004\end{array}$ & AÑO 2005 & AÑO 2006 & TOTAL \\
\hline 58 & 63 & 81 & 68 \\
\hline
\end{tabular}

PROCURADURIA PROVINCIAL

\begin{tabular}{|c|c|c|c|}
\hline $\begin{array}{c}\text { AÑO } \\
2004\end{array}$ & $\begin{array}{c}\text { AÑO } \\
2005\end{array}$ & $\begin{array}{c}\text { AÑO } \\
2006\end{array}$ & TOTAL \\
\hline 83 & 64 & 20 & 167 \\
\hline
\end{tabular}

\footnotetext{
18 Oficio No.130-60-021-150 de 2007 suscrito por Martha Eugenia Andrade López Directora Técnica de Responsabilidad Fiscal y Jurisdicción Coactiva.

19 Oficio ORF 1049 de 2007 suscrito por Edgar Leonel Conta Jefe de Oficina de Responsabilidad Fiscal.

20 Oficio 80413-01114 de 2007 suscrito por Cecilia Quimbayo Carvajal Coordinadora de Gestión.
} 
PROCURADURÍA REGIONAL

\begin{tabular}{|c|c|c|c|}
\hline $\begin{array}{c}\text { AÑO } \\
2004\end{array}$ & $\begin{array}{c}\text { AÑ } \\
2005\end{array}$ & $\begin{array}{c}\text { AÑO } \\
2006\end{array}$ & TOTAL \\
\hline 93 & 48 & 19 & 160 \\
\hline
\end{tabular}

AUDITORÍA GENERAL DE LA REPÚBLICA

\begin{tabular}{|c|c|c|c|}
\hline $\begin{array}{l}\text { AÑ } \\
2005\end{array}$ & $\begin{array}{l}\text { AÑ } \\
2006\end{array}$ & $\begin{array}{l}\text { AÑ } \\
2007\end{array}$ & TOTAL \\
\hline 4 & 1 & 1 & 6 \\
\hline
\end{tabular}

Teniendo en cuenta el espacio disponible para la publicación de este artículo, en la presentación de los resultados se hará referencia únicamente a los principales factores y agentes que generan corrupción en el Huila.

\section{RESULTADOS}

HECHOS INVESTIGADOS

EN LA CONTRALORÍA

MUNICIPAL, DEPARTAMENTAL

Y DE LA REPÚBLICA

Teniendo en cuentaque los hechos investigados presentan una gran variedad de matices, se agruparon en dos grandes temas a fin de logar un mejor análisis. De un lado, se agruparon los hechos que tienen que ver con la actividad de contratación y de otro lado, se tomaron en un solo grupo los hechos relacionados con la actividad administrativa.

En el caso de la Contraloría municipal se determinó que los resultados que para el año 2004, el 57\% de las personas investigadas están relacionadas con hechos relacionados con la contratación estatal; mientras que para el año 2005 el 71,42\% de las personas investigadas se relacionan con trámites administrativos, situación que se repitió en el año 2006 con un porcentaje del 58,62.

Para el caso de la Contraloría Departamental en relación con los hechos investigados, se determinó que los actos de corrupción alcanzaron un porcentaje alto: 2004 43,10\%, 2005 56,09\% y 2006 60,49\%.

Por último en el caso de la Contraloría General de la República se concluyó que existe un alto porcentaje de hechos relacionados con actos de corrupción, los cuales alcanzaron un porcentaje significativo: 2004 98,27\%, $200585,71 \%$ y 2006 29,62. Igualmente se advierte que de las tres contralorías, la del nivel nacional tiene los porcentajes más altos en procesos relacionados con corrupción.

\section{AGENTES SANCIONADOS POR LA CONTRALORÍA MUNICIPAL, DEPARTAMENTAL Y GENERAL DE LA REPÚBLICA}

En la Contraloría municipal se destaca que de los tres años analizados, en dos se presenta un mayor porcentaje de personas procesadas en materia de actividad propiamente administrativa y en tan solo un año, el tema de la contratación estatal fue el que mayor porcentaje de procesos arrojó. Ésta situación puede llevarnos a deducir una debilidad en el manejo de los procesos internos administrativos por parte de los funcionarios de la Alcaldía de Neiva, lo que conlleva a que los trámites internos se hagan de forma errada y equivocada llevando con ello a un desorden en la gestión desempeñada por cada uno de ellos y en riesgo de investigaciones fiscales.

Se realizó una cuantificación de los actos de corrupción a nivel fiscal en el nivel municipal: Año 2004: 37 casos equivalentes al 75,67\%; en el año 200521 casos equivalentes al 52,38\% y en el año 200629 casos equivalente a 79,31\%. Este ejercicio refleja que en el nivel municipal el año 2004 el 75,67\% de los investigados lo fueron por actos de corrupción, en el 2005 un 52,38\% y para el año 2006 un 79,31\%.

Para el caso de la Contraloría Departamental 
se determinó que los actos de corrupción alcanzan un porcentaje alto: $200443,10 \%$, $200556,09 \%$ y $200660,49 \%$.

Similar a la tendencia de las contralorías municipal y departamental, en la Contraloría General de la República los agentes que más generan procesos fiscales son en primer lugar los contratistas y muy seguido los alcaldes municipales junto con los servidores de nivel directivo.

Con relación al nivel jerárquico de los agentes generadores de corrupción, en la Contraloría General de la República se observaron unos porcentajes importantes en el nivel directivo que en el año 2004 fue de $43 \%$, en el año 2005 descendió un poco al $33 \%$ y en el año 2006 se ubicó en el $25 \%$. Esta tendencia es igual a la expresada en la Contraloría Municipal y Departamental en las que igualmente se refleja una corrupción de cuello blanco, pues es el nivel directivo dentro de la escala jerárquica administrativa, la que es investigada mayormente.

\section{AGENTES DISCIPLINADOS EN LA PROCURADURÍA PROVINCIAL Y REGIONAL}

Con relación a la Procuraduría Provincial se tienen los siguientes resultados relacionados con los agentes involucrados en procesos disciplinarios.

\section{AÑO 2004}

\section{Tabla No.1}

Dos se encuentran en investigación que corresponde al $2 \%$.

\begin{tabular}{|l|c|}
\hline Alcalde Municipal & 26 \\
\hline Concejal & 14 \\
\hline Gerente EEPP & 4 \\
\hline Secretaria de desarrollo & 4 \\
\hline Personero municipal & 3 \\
\hline
\end{tabular}

\begin{tabular}{|c|c|}
\hline Jefe de planeación municipal & 3 \\
\hline $\begin{array}{l}\text { Director administrativo dirección } \\
\text { financiera y tesorería de Neiva }\end{array}$ & 2 \\
\hline Gerente EEPP IMOC & 2 \\
\hline Secretario de infraestructura vial & 2 \\
\hline $\begin{array}{l}\text { Asesor oficina contratación } \\
\text { municipal }\end{array}$ & 2 \\
\hline Jurado de votación & 2 \\
\hline Tesorero municipal & 2 \\
\hline Ex Gerente EPM & 1 \\
\hline Coordinador sisben & 1 \\
\hline Ex-Alcalde Municipal & 1 \\
\hline Director de justicia municipal & 1 \\
\hline Funcionario EEPP - IMOC & 1 \\
\hline $\begin{array}{l}\text { Comandante de la } \\
\text { estación de policía }\end{array}$ & 1 \\
\hline Secretaria relaciones públicas & 1 \\
\hline Secretaria administrativa de Neiva & 1 \\
\hline Almacenista municipal & 1 \\
\hline Almacenista EEPP & 1 \\
\hline Asesor alcalde de Neiva & 1 \\
\hline $\begin{array}{l}\text { Director administrativo de } \\
\text { emergencias y desastres }\end{array}$ & 1 \\
\hline $\begin{array}{l}\text { Jefe departamento } \\
\text { jurídico municipal }\end{array}$ & 1 \\
\hline Curador urbano municipal & 1 \\
\hline $\begin{array}{l}\text { Tesorero ESE Carmen } \\
\text { Emilia Ospina }\end{array}$ & 1 \\
\hline
\end{tabular}




\section{AÑO 2005}

\section{TABLA NO.2}

Once se encuentran en investigación que corresponde al $18 \%$.

\begin{tabular}{|c|c|}
\hline Alcalde Municipal & 25 \\
\hline Personero municipal & 3 \\
\hline $\begin{array}{l}\text { Miembro junta directiva } \\
\text { del centro de salud }\end{array}$ & 4 \\
\hline Concejal & 2 \\
\hline Jurado de votación & 2 \\
\hline Gerente EEPP & 1 \\
\hline Gerente ESE Yaguará & 1 \\
\hline $\begin{array}{l}\text { Sub-Gerente administrativa } \\
\text { EEPP Neiva }\end{array}$ & 1 \\
\hline Asesor de la Alcaldía & 1 \\
\hline Profesional Universitaria & 1 \\
\hline Directora municipal de Justicia & 1 \\
\hline Auxiliar en el manejo de la cárcel & 1 \\
\hline Asesor control interno & 1 \\
\hline Director cárcel municipal & 1 \\
\hline $\begin{array}{l}\text { Secretario de la Procuraduría } \\
\text { General de la Nación }\end{array}$ & 1 \\
\hline Juez de instrucción penal militar & 1 \\
\hline Asamblea, accionista Mercaneiva & 1 \\
\hline Director administrativo de emergencias & 1 \\
\hline $\begin{array}{l}\text { Coordinador Gr 12: } \\
\text { Alcaldía Campoalegre }\end{array}$ & 1 \\
\hline $\begin{array}{l}\text { Secretaria administrativa de } \\
\text { la Alcaldía de Neiva }\end{array}$ & 1 \\
\hline Tesorero municipal de Neiva & 1 \\
\hline $\begin{array}{l}\text { Secretario de desarrollo } \\
\text { Social Alcaldía de Neiva }\end{array}$ & 1 \\
\hline Gerente Hospital Divino Niño & 1 \\
\hline Agente policía Nacional & 1 \\
\hline $\begin{array}{l}\text { Secretario de Infraestructura } \\
\text { y desarrollo }\end{array}$ & 1 \\
\hline
\end{tabular}

\section{AÑO 2006}

\section{TABLA NO.3}

Uno se encuentra en averiguación que corresponde al $5 \%$.

\begin{tabular}{|l|c|}
\hline Alcalde Municipal & 11 \\
\hline Concejal & 6 \\
\hline Director de justicia municipal & 1 \\
\hline Secretaria de desarrollo & 1 \\
\hline
\end{tabular}

En la Procuraduría Provincial los hechos generadores de investigación disciplinaria son de la más diversa índole. Sin embargo, se resalta que el hecho más recurrente es el relacionado con la contratación administrativa. Este tema contiene comportamientos tales como irregularidades en el procedimiento de contratación y en su ejecución, liquidación de contratos sin el cumplimiento de los requisitos legales, suscribir contratos contrariando la Ley 715/01, irregularidades en el manejo de los pliegos de la invitación pública, sobrecostos de los contratos, etc. La investigación determinó unos porcentajes de corrupción que se presentan a continuación: año 200483 casos equivalente al $28,12 \%$; año 200620 casos equivalente al $30 \%$; año 200483 casos equivalente al 4.81\%.

En relación con los datos del disciplinado, específicamente lo referente al cargo ejercido, la investigación arrojó con claridad que el funcionario público con mayor cantidad de procesos disciplinarios es el alcalde municipal, correspondiendo en cada año una cantidad importante: 2004 26; 2005 25; 200611 . Se observa igualmente que los servidores que más quejas poseen son los del sector central de la alcaldía de Neiva, situación que es explicable debido a la gran cantidad de funcionarios que posee el sector central de la alcadia, cifra que está alrededor de los 350 funcionarios. Así mismo se verifica que unos pocos servidores pertenecen a entidades diferentes a la alcaldía de Neiva, tales como el Comandante de la estación de policía, Secretario de la Procuraduría General de la Nación, Juez de instrucción penal militar, Personero municipal y el 
CoordinadorGrado 12 dela Alcaldía Campoalegre. Se resalta la existencia de particulares, los cuales a pesar de no tener la calidad de servidores públicos, en estos casos ejecutan actividades públicas por lo que son sujetos disciplinables como son los jurados de votación, el curador urbano municipal, y un miembro junta directiva del centro de salud.

Las tablas reseñan con claridad que el funcionario públicoconmayorcantidaddeprocesosdisciplinarios es el alcalde municipal, correspondiendo en cada año una cantidad importante: 2004 26; 2005 25; 2006 11. Se observa igualmente que los servidores que más quejas poseen son los del sector central de la Alcaldía de Neiva, situación que es explicable debido a la gran cantidad de funcionarios que posee el sector central de la misma, cifra que está alrededor de los 350 funcionarios. Así mismo se verifica que unos pocos servidores pertenecen a entidades diferentes a la Alcaldía de Neiva, tales como el Comandante de la estación de policía, Secretario de la Procuraduría General de la Nación, Juez de instrucción penal militar, Personero municipal y el Coordinador Gr 12: Alcaldía Campoalegre. Se resalta la existencia de particulares, los cuales a pesar de no tener la calidad de servidores públicos, en estos casos ejecutan actividades públicas por lo que son sujetos disciplinables: Jurados de votación, Curador urbano municipal, Miembro junta directiva del centro de salud.

Con relación al nivel del cargo de los funcionarios sancionados por la Procuraduría Provincial se tiene:

\section{GRÁFICA NO.1}

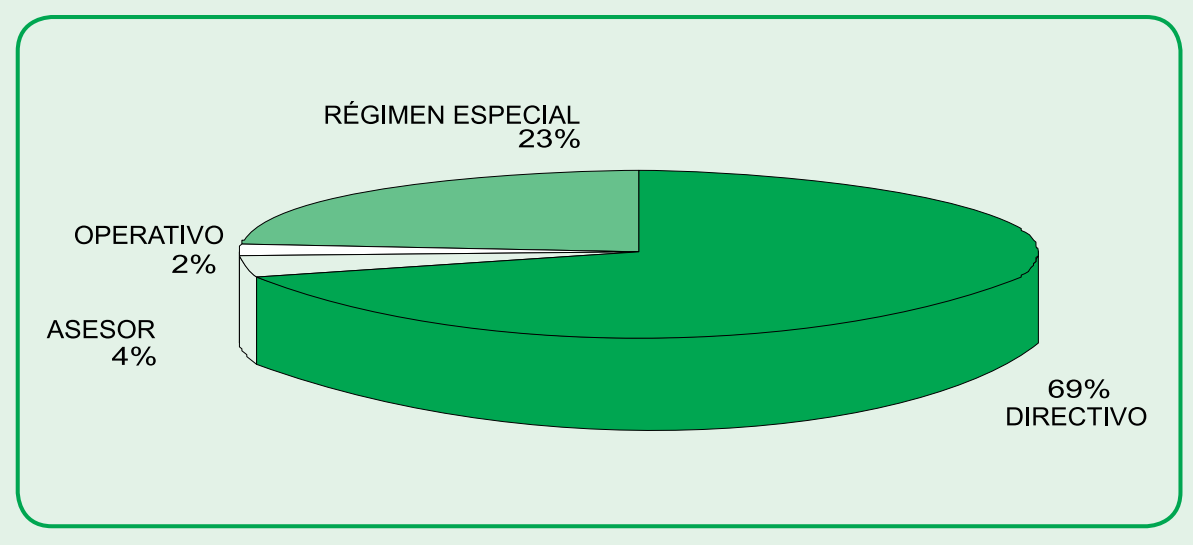

AÑO 2005

GRÁFICA NO.2

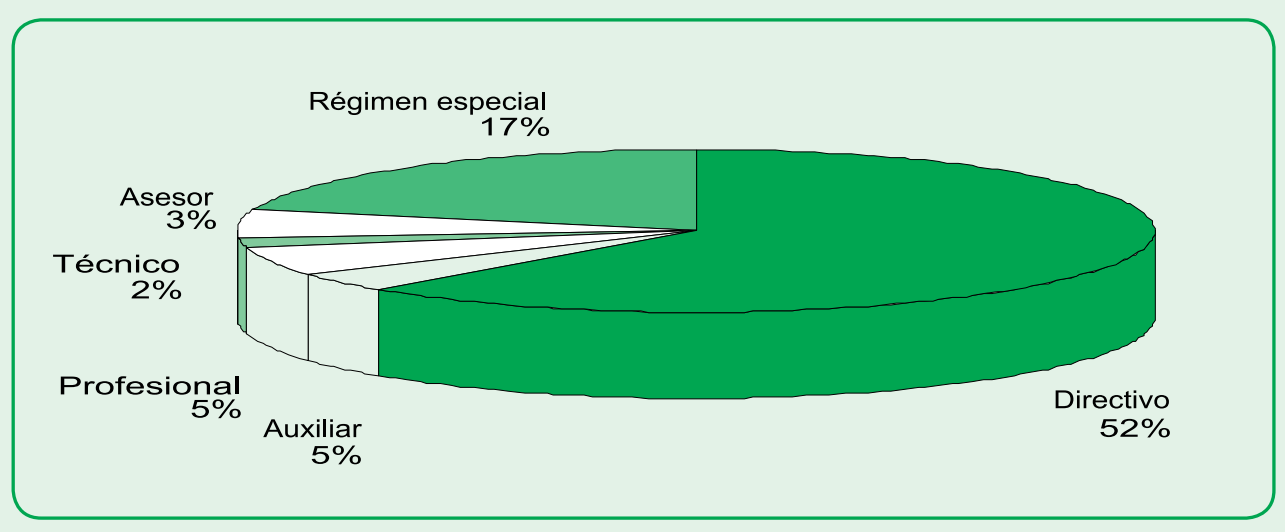




\section{AÑO 2006 \\ GRÁFICA NO.3}

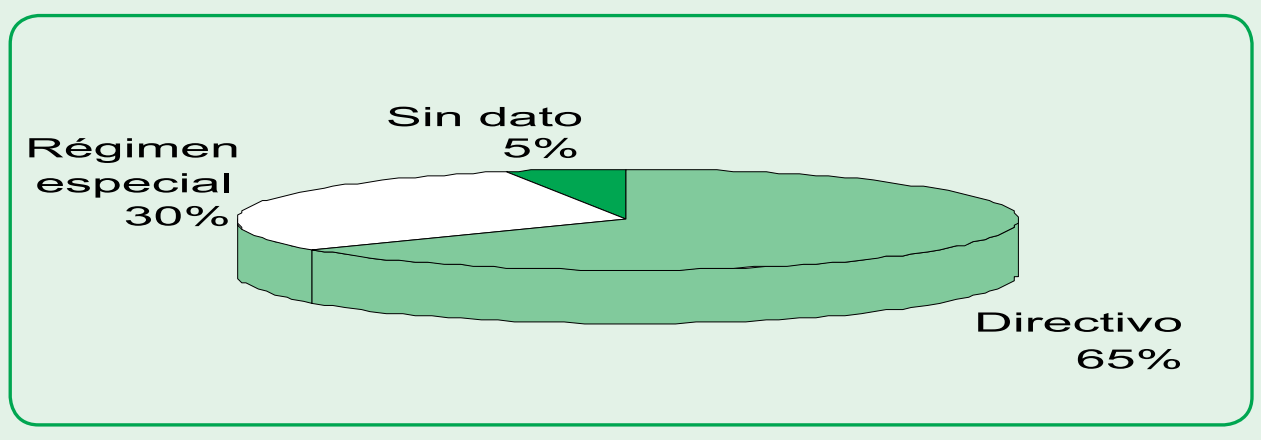

Estas gráficas reflejan de manera clara, que los servidores que más violan la norma disciplinaria, según los procesos de la Procuraduría Provincial, son los del nivel directivo en todos los tres años analizados $(69 \%, 52 \%, 65 \%)$. Este resultado podría tener una explicación.

Según lo establece el artículo 47 de la Ley 909 de 2004 (ley de la administración pública y la carrera administrativa), los servidores del nivel directivo son aquellos funcionarios que desarrollan funciones de naturaleza gerencial, que tienen una responsabilidad directiva en la administración pública de la rama ejecutiva de los órdenes nacional y territorial, desempeñan cargos de libre nombramiento y remoción y en caso del nivel territorial (departamentos y municipios) corresponden a los secretarios de despacho, de director, gerente; rector de institución de educación superior distinta a los entes universitarios autónomos.

De acuerdo a dicha ley, estos empleos comportan una gran responsabilidad por la gestión y por un conjunto de funciones cuyo ejercicio y resultados son posibles de ser medidos y evaluados.

Al ser los servidores que se encuentran en la cúspide jerárquica, nominadores del gasto y que dirigen la entidad respectiva, son también los servidores que más funciones delicadas y de sumo cuidado tienen, pero que a su vez ostentan mayor poder y posibilidad de determinar beneficios particulares propios o a terceros. Es por ello que se pueden ver comprometidos en hechos o situaciones reprochables disciplinariamente, sin contar con las quejas presentas en su contra por móviles eminentemente políticos o personales.

En relación con los resultados de la Procuraduría Regional, las tablas mostraron que los hechos generadores de investigación disciplinaria son muy diversos. Contrario a lo reflejado en el caso de la Procuraduría Provincial, en la Procuraduría Regional el hecho más recurrente no es el relacionado con la contratación administrativa.

\section{AÑO 2004 (93 QUEJAS)}

- Presuntas irregularidades en contratación 9

- Exigir dinero para no ponerlos a disposición judicial por cargar alucinógenos 4

- Indebida utilización de dineros 2

- Cobrar dinero para comisiones que no cumplió de acuerdo a las constancias solicitadas 1

TOTAL $16(17,20 \%)$

\section{AÑO 2005 (48 QUEJAS)}

Presunta irregularidad por utilizar vehiculo oficial fuera de las funciones 3

Presunta irregularidad para celebrar concesiones con la federación nacional de cafeteros 2

Presunta irregularidad al recibir doble asignación del erario público 1 
Presunta irregularidad por adquisición de celular con erario público 1

Posibles irregularidades por doble vinculación, erario público 1

TOTAL $.8(16,66 \%)$

\section{AÑO 2006 (19 QUEJAS)}

Presunta irregularidad de operador de servicios al aprovecharse de su cargo para hacer cobro de una deuda personal 1

Presunta irregularidad en el mal uso del vehiculo del INPEC 1

TOTAL $.2(10,52 \%)$

Aunque el anterior ejercicio podría resultar algo impreciso debido a que faltaría especificar algunas conductas para precisar si existió aprovechamiento particular, se puede observar que un muy bajo porcentaje, las conductas disciplinadas en la Procuraduría son actos de corrupción. La mayor parte de ellas son conductas que no revisten un aprovechamiento o beneficio particular y por lo tanto no se le podrían tildar como corruptos los sancionados.

Este ejercicio refleja que en el año 2004 la corrupción fue del 17,20\%) en el año 2005 del $6,66 \%$ y en el año 2006 correspondió al 10,52\%.

Comparando estas cifras con la Procuraduría Provincial se asimilan en cuanto que son también muy bajas: en el 2004 fue del $4,81 \%$, en el 2005 del $28,12 \%$ y para el año 2006 del $30 \%$.

Con relación a nivel jerárquico, los resultados reseñan una diversidad de funcionarios investigados de la más diversa vinculación, sin que se pueda hacer un comentario especial respecto a alguna categoría o entidad. Solo en el año 2004 de observa una mayoría muy leve de investigaciones dirigidas hacia funcionarios del sector educación (26), pero en los demás años no existen mayoría contundentes. Esto se debe al factor de competencia de la Procuraduría Regional, la cual tiene la facultad de investigar funcionarios de todo el departamento del Huila y de todas las entidades y sectores.

Los cuadros reseñan una diversidad de funcionarios investigados de la más diversa vinculación, sin que se pueda hacer un comentario especial respecto a alguna categoría o entidad. Solo en el año 2004 de observa una mayoría muy leve de investigaciones dirigidas hacia funcionarios del sector educación (26), pero en los demás años no existen mayoría contundentes. Esto se debe al factor de competencia de la Procuraduría Regional, la cual tiene la facultad de investigar funcionarios de todo el departamento del Huila y de todas las entidades y sectores.

En cuanto al resultado de las sanciones se observa que los porcentajes de sanción son bastante altos en la Procuraduría Regional en comparación con la Procuraduría Provincial. Si comparamos estos dos ítems tenemos lo siguiente:

\section{CUADRO NO.5}

\begin{tabular}{|c|c|c|}
\hline AÑO & $\begin{array}{c}\text { Sancion } \\
\text { Provincial }\end{array}$ & $\begin{array}{c}\text { Sancion } \\
\text { Regional }\end{array}$ \\
\hline 2004 & $11 \%$ & $64 \%$ \\
\hline 2005 & $19 \%$ & $54 \%$ \\
\hline 2006 & $10 \%$ & $79 \%$ \\
\hline
\end{tabular}

Lo anterior podría indicar que las absoluciones son inversamente proporcionales en las dos entidades, pero no es así. En el año 2004, la Procuraduría Provincial tuvo un porcentaje más alto de absoluciones que la Regional pero en los dos años siguientes disminuyó hasta llegar a ser inferior en el 2006 que en la Regional.

\section{CUADRO NO.6}

\begin{tabular}{|c|c|c|}
\hline AÑO & $\begin{array}{c}\text { Absolucion } \\
\text { Provincial }\end{array}$ & $\begin{array}{c}\text { Absolucion } \\
\text { Regional }\end{array}$ \\
\hline 2004 & $40 \%$ & $22 \%$ \\
\hline 2005 & $28 \%$ & $29 \%$ \\
\hline 2006 & $5 \%$ & $21 \%$ \\
\hline
\end{tabular}




\section{RESULTADOS DE LA AUDITORIA GENERAL DE LA REPÚBLICA}

En la consulta realizada a la Auditoría en la ciudad de Neiva, sólo se encontraron 6 procesos desde el año 2005. En el año 2004 no hubo procesos pero sí en el año 2007. A pesar de que el estudio se planteó inicialmente para los años 2004, 2005 y 2006, el Grupo optó por analizar el del año 2007 habida cuenta de la inexistencia de procesos en el año 2004. Se encontraron los siguientes datos:

\section{PERSONAS INVESTIGADAS}

\section{TABLA NO.109}

\begin{tabular}{|c|c|c|c|}
\hline $\begin{array}{c}\text { AÑ } \\
2005\end{array}$ & $\begin{array}{c}\text { AÑO } \\
2006\end{array}$ & $\begin{array}{c}\text { AÑO } \\
2007\end{array}$ & TOTAL \\
\hline 4 & 1 & 1 & 6 \\
\hline
\end{tabular}

Se observa que el universo es muy reducido, diferente a las cifras obtenidas en los órganos de control fiscal y disciplinario.

\section{CONCLUSIONES}

- Contrario a lo que todos creen, la corrupción administrativa en Neiva y el Huila no es muy alta, al menos eso arroja el análisis de las decisiones de los órganos de control. La corrupción en términos técnicos, abunda en los niveles jerárquicos altos (principalmente nivel profesional, asesor y directivo) y está muyrelacionadaconasuntos procedimentales, es decir, aspectos meramente formales.

- En las contralorías se observó que el hecho más recurrente en investigación es la contratación administrativa. Sin embargo el detrimento patrimonial no es muy alto desde la perspectiva de sus decisiones.

- Los resultados de la Procuraduría Regional revelan mayor nivel sancionatorio que la Procuraduría Provincial, lo cual puede tener diversas lecturas: o es más eficiente la primera o la segunda es mas garantista en la protección de los derechos de los disciplinados.

- El resultado de la Auditoría es muy pobre teniendo en cuenta que solo ha tenido una sola sanción administrativa. Habría que realizar un análisis de las actividades administrativas de control con el fin de determinar su eficacia.

\section{BIBLIOGRAFÍA}

AYALA, Jorge Enrique. La Responsabilidad de los Servidores Públicos. Bogotá: Ediciones Doctrina y Ley Ltda. 2005, 876 p.

CUESTAS ALGARRA Alcibiades y RONDEROS SALGADO Arturo. La Ley de Acción de Repetición y el servidor público. Implicaciones de orden disciplinario. Bogotá: Ediciones Jurídicas Gustavo Ibáñez. 2004, 287 p.

EIGEN, Peter. Las Redes de la Corrupción. La Sociedad Civil contra los abusos del poder. Barcelona (España): Planeta, 2003319 p.

LAPORTA Francisco J y ALVAREZ Silvina. La Corrupción Política. (Editores). Madrid: Alianza Editorial. 1997, 372 p.

ALGARRA LOBO Mario Iván. No Mas Corrupción. Estrategia Preventiva Para Combatirla. Bogotá: Ediciones jurídicas Ibáñez, 2005, $333 \mathrm{p}$.

KIMBERLY Ann Elliot. La Corrupción en la Economía Global. (Editora). México: Editorial Limusa Noriega Editores, 2001, 292 p. 
MALEM SEÑA Jorge F. La Corrupción. Aspectos éticos, económicos políticos y jurídicos. Barcelona (España), 2002, 250 p.

ROSE-ACKERMAN Susan. La Corrupción Y Los Gobiernos. Causas, Consecuencias y Reforma. Madrid: Siglo XXI de España editores, 2001, 366 p.

QUERUBIN LONDOÑO, Rodrigo. La lucha anticorrupción y la ética pública y privada. Bogotá: Editorial Carrera séptima, 2005, 319 p.

CORPORACIÓN TRANSPARENCIA POR COLOMBIA. CAPITULOTRANSPARENCIA INTERNACIONAL. Informe Anual 2006. Bogotá 2006. 44 p.

CORPORACIÓN TRANSPARENCIA POR COLOMBIA. CAPITULOTRANSPARENCIA INTERNACIONAL. Colección Cuadernos de Transparencia. No.12 Monitoreo Ciudadano a herramientas de transparencia en la contratación pública. Sin fecha. 99 p.

CORPORACIÓN TRANSPARENCIA POR COLOMBIA. CAPITULOTRANSPARENCIA INTERNACIONAL. Colección Cuadernos de Transparencia. No.11 Convención de las Naciones Unidas contra la Corrupción y Derecho interno colombiano. Diciembre 2006.159 p.

\section{TRANSPARENCY}

INTERNACIONAL. Curbing Corruption in Public Procurement. The Global coalition agains corruption. 2006. $230 \mathrm{p}$.

\section{CORPORACIÓN}

TRANSPARENCIA

POR COLOMBIA. Capítulo Transparencia Internacional. Índice de transparencia nacional. Resultados 2004-2005 Entidades públicas nacionales. Colección Documentos Observatorio de Integridad. Bogotá Diciembre de 2006. 71 p.
MINISTERIO DE JUSTICIA Y DEL DERECHO. Dirección General de Políticas Jurídicas y Desarrollo Legislativo. Contra la Corrupción: 18 meses después. Santa fe de Bogotá. Diciembre de 2006. 509 p.

PROCURADURÍA GENERAL DE LA NACIÓN. Instituto de Estudios del Ministerio Público. Manual para la Transparencia de la Gestión Territorial. Bogotá: abril de 2004. 291.

PRESIDENCIA DE LA REPÚBLICA VICEPRESIDENCOA DE LA REPUBLICA. Propuesta de una Política de Estado para el control de la corrupción. Bogotá, sin fecha. $116 \mathrm{p}$.

\section{(FOOTNOTES)}

1 Oficio No.2114 de 2007 suscrito por Jorge Elicer Andrade Reina Secretario Provincial Neiva.

2 Oficio No.D.706 de 2007 suscrito por Delia del Socorro Cedeño Poveda.

3 Oficio No.130-60-021-150 de 2007 suscrito por Martha Eugenia Andrade López Directora Técnica de Responsabilidad Fiscal y Jurisdicción Coactiva.

4 Oficio ORF 1049 de 2007 suscrito por Edgar Leonel Conta Jefe de Oficina de Responsabilidad Fiscal.

5 Oficio 80413-01114 de 2007 suscrito por Cecilia Quimbayo Carvajal Coordinadora de Gestión. 